\title{
Research on the Resilience of Urban Emergency Management System
}

\author{
Yuanhui Zhang \\ Guangdong Teachers College of Foreign Language and Arts, Guangzhou, Guangdong, China
}

\begin{abstract}
The outbreak of emergencies has triggered people's thinking about the ability of urban emergency management system to deal with emergencies. Under the current situation, the traditional urban emergency management mode has been unable to cope with the new problems of unexpected events. The author believes that the government led urban emergency management system and social organizations, enterprises, non-profit organizations and the public should form an "emergency social network". Their collaboration is actually based on their self-organizing operation, making full use of mutual feedback and feedback with the environment, adaptively changing the organic combination of mutual relations, so as to make the city as a whole. It is a complex operation process of the system from disorder to order. This process is not only to improve the resilience of the city by optimizing the management function of the government emergency system, but also to achieve the overall optimization of the system by combining the improvement of the response ability of social organizations and the improvement of citizens' quality, so as to achieve the response performance of "the whole is greater than the sum of parts".
\end{abstract}

Keywords: urban resilience; resilience thinking; emergency system; resilience management

\section{Introduction}

Urban emergency system is a complex system with multi-level structure. The resilience theory requires us to pay attention to the relationship between different scales when carrying out emergency management. If we only pay attention to the structure and changes within a certain scale, the management must fail. For the urban emergency management system, we must pay attention to the relationship between the horizontal and vertical scales of the system. In addition to the non-linear relationship between the internal levels of the system, we must also pay attention to the cross scale non-linear relationship between the social organizations, enterprises and the public related to the emergency system. Because of the structure and dynamic changes in any scale and the response of the main body to emergencies in that scale, the system state and dynamic changes in other scales will have a huge impact. With the enhancement of the awareness of emergency crisis, the compactness of the government emergency system, social organizations and the public is also increasing. Because of the mutual feedback, they are developing adaptively in continuous learning, so that the resilience of the government emergency system and emergency social network is also improved. Not only that, the government emergency system, emergency social network and the the resilience of urban system composed of social environment has also been improved. It shows that the government emergency system and social network are a kind of equal cooperative relationship. In the process of the development of this cooperative relationship to constantly respond to various crises, it is necessary to

Copyright (C) 2020 by author(s) and Frontier Scientific Research Publishing Inc.

This work is licensed under the Creative Commons Attribution International License (CC BY 4.0).

http://creativecommons.org/licenses/by/4.0/ 
continuously enhance the ability of the system to absorb the disturbance of emergencies, reduce the impact brought by uncertainty, so as to realize the resilience of the city to respond to emergencies. And their ability to participate in the management of emergency and control system resilience is adaptability.

\section{Resilience and Resilience Thinking}

Resilience is a typical interdisciplinary vocabulary, which is widely used in many research fields such as materials science, economics, psychology, ecology, histology, anthropology, sociology, engineering and computer science. Resilience originated in the field of mechanics and physics in the $1850 \mathrm{~s}$, and was widely used in different fields. In the 1950s-1980s, resilience was used in western psychological research to describe the recovery after trauma. In 1973, Holling, an ecologist from Canada, introduced resilience into the study of ecosystem stability. Since the 1990s, the academic research on elasticity has gradually extended from natural ecology to human ecology, and more research subjects have emerged, such as social resilience, urban resilience, organizational resilience, rural resilience and community resilience. Although after decades of debate, there is still no consensus on the concept of elasticity. Gunderson and Holling defined resilience as "the ability of the system to withstand interference and maintain its function and control, that is, the resilience is determined by the interference magnitude that the system can withstand and maintain its function."

In the past 20 years, the academic community has studied the resilience of different systems in various fields. Under the framework of social ecosystem, a kind of elastic thinking and management theory about social ecosystem has been formed. Since the 1990s, the volume of literature on social ecosystem and resilience has grown rapidly. The new thinking mode of resource management recommended by Resilience Alliance is resilience thinking, which is considered as the theoretical basis of sustainable development management by many scholars. The key of sustainability is to regard social ecosystem as a complex system which is in constant change and adapts to the environment actively, and to manage the complex system effectively with elastic thinking, and to achieve the goal of sustainable development by enhancing the system resilience.

\section{Vulnerability and Urban Elasticity of Urban Emergency Management System}

How to deal with various incidents that expose the vulnerability of the city emergency management system? It is mainly manifested in the following aspects: first, the response, command and coordination ability of the emergency system is insufficient, and social organizations and the public are not actively involved in the prevention, control and disposal of the epidemic, which is caused by the lack of sensitivity and awareness of the emergency system to emergencies. Second, the ability of the emergency system in the application of information technology is insufficient, and the emergency system is not properly assisted by big data technology. Third, the overall quality and overall awareness of citizens are weak, which is also a problem of cognitive level. In addition, excessive emphasis on the classification of epidemic level and the responsibility of urban territory makes the city's supporting medical forces, social resources available for regulation and control, as well as the emergency command ability of local governments to face severe challenges in major emergencies.

Since 2000, in response to the new ideas and new methods of urban emergencies, the research on urban resilience has attracted great attention from governments, scientific research institutions and social organizations. Resilience Alliance proposed to examine the urban system from the perspective of resilience. From the current research, researchers at home and abroad mainly focus on the complexity and vulnerability of urban system from the perspective of resilience, the means of urban system using information technology, the supply chain mechanism of urban system and urban social dynamics. In order to improve the overall governance ability of the city and enhance the resilience of the urban system, we should analyze and study the power mechanism. To sum up, urban elasticity refers to the adaptability and transformation ability of each subsystem and corresponding community and environment of the city to maintain the normal operation of social order 
and economic development and guarantee the personal and property safety of citizens under the interference of sudden uncertainty through reasonable preparation and effective utilization of materials and equipment.

\section{How to Enhance Urban Emergency Management System's Resilience}

First of all, all provinces, cities, districts and counties can reserve medical material resources in the form of hospital self storage or by agreement with enterprises, and then establish emergency material reserve management system through big data technology. Through the monitoring and allocation of material resources, dynamic network management can be realized so that emergency events can be reasonably called at any time. However, due to the timeliness of medical material resources, on the one hand, the provincial and municipal health committees should cooperate with social organizations to carry out the storage of medical materials, on the other hand, they should sign material supply guarantee with productionoriented enterprises to achieve multi-channel material storage and supply, so as to ensure that reserve materials can be effectively transferred or put into production in case of emergencies.In addition, the allocation and scheduling of emergency resources also need scientific planning, which can realize the optimal allocation and scheduling of material resources through modeling with the help of big data and simulation model. Secondly, the state should strengthen the construction of national public health emergency infrastructure from provinces, cities, districts and counties to villages, just like the road into the countryside in the same year can lead farmers out of poverty. Only by increasing the investment in public health emergency medical infrastructure, can people's health and safety be effectively guaranteed. In other cities, especially in small cities, the medical mechanism configuration and level are worse, let alone the emergency medical ward. Finally, it is about the allocation and reserve of talents in the field of medical public health. At present, the hospital system is not only in short supply of children doctors, but also in short supply of epidemic prevention talents. The infection is closely related to the shortage of medical professionals who have professional knowledge of epidemic prevention, such as inadequate professional knowledge when caring for patients, inadequate protection for their own epidemic prevention, and so on. Therefore, these problems should be considered in the health system. Only with sufficient medical material resources, planning and building reasonable emergency and epidemic prevention places and increasing the training and matching of epidemic prevention professionals, can we have enough resilience to deal with public health emergencies.

\section{Conclusions}

In the past decade, it has been found that the effective emergency management depends on the degree of cooperation among multiple subjects in the process of responding to all kinds of emergencies in various cities at home and abroad. It is undeniable that the leader of urban emergency response must be the government department, because the unified deployment ability of the government in the face of major emergency has natural advantages, but it can not negate the positive role of social organizations and the public. As the urban system is more and more complex and the emergency events are more and more diverse and unpredictable, the emergency system management with the government as the absolute center The mode of management has fallen behind. At present, the core problem of urban emergency system management is the cross level adaptive learning and collaborative response among the main bodies. There are two meanings in this paper. One is the nonlinear interaction between different subjects and different levels of subjects in the emergency system. The other is the cooperative cooperation between the subjects of the system and other organizations. This is just the characteristics of system integrity and coordination emphasized by elasticity theory.

\section{Conflicts of Interest}

The author declares no conflicts of interest regarding the publication of this paper.

\section{References}

[1] Cui P., Li D.Z., Chen H.X. and Cui Q.B. (2018). Review and Prospect of Community Resilience Research: 
Concept, Dimension and Evaluation. Modern City Research, (11): 119-125.

[2] Anna B., Domenico A. and Gaetano M. (2015). Developing an Integrated Framework to Quantify Resilience of Urban Systems aginst Disasters. Natural Hazards, 78(3): 1729-1748.

[3] Li Dezhi., Han Y., Chen Y.C. and Li Q.M. (2016). Review of Overseas Research on Social Ecosystem Elasticity. Modern Management Science, (1): 100-102.

[4] Alexander D.E. (2013). Resilience, Disaster Risk Reduction: An Etymological Journey. Natural Hazards and Earth System Science, 13(11): 2707-2716.

[5] Holling C.S. (1973). Resilience and Stability of Ecological Systems. Annual Review of Ecology \& Systematic, 4(1):1-23.

[6] Shao Y.W. and Xu J. (2015). Urban Resilience: A Conceptual Analysis Based on International Literature Review. International urban planning, 30(2): 48-54.

[7] Gunderson L.H. and Holling C.S. (2001). Understanding the Comp Lexity of Economic, Ecological and Social Systems. Ecosystems, (6): 390-405.

[8] Peng S.L. (2011). Ecological View of Development: Flexible Thinking. Acta Ecologica Sinica, (19): 5433-5436.

[9] Brian W. and David Salt. (2006). Resilience Thinking -- Sustaining Ecosystems and People in a change world. Island Press, Washington DC.

[10] Zhang Yuanhui. (2019). Social Ecosystem Based on Complexity Theory -- An Empirical Analysis of Elastic Management of Haizhu Wetland Park. Journal of Guizhou University (SOCIAL SCIENCE EDITION), (05): 116-122. 